\title{
Can food influence female sexual functions? Views of a sample of married Egyptian women
}

\author{
Original \\ Article \\ Ihab Younis ${ }^{1}$,Hend Abdalla ${ }^{2}$, Ghada Shams ${ }^{1}$ \\ ${ }^{1}$ Department of Dermatology and Andrology, Faculty of Medicine, Benha University, Benha \\ and ${ }^{2}$ El-Menshawy Hospital, Tanta, Egypt
}

\begin{abstract}
Background: Since antiquity, people were looking for specific foods in order to improve their sexual performance. Although food may have an obvious effect on sexuality in both men and women, its effect on female sexual function is usually underestimated.

Objective: The current study aimed to evaluate the impact of food on various aspects of sexuality in women.

Patients and Methods: This cross-sectional study was carried out on 300 married women aged 20-50+ years having a regular sexual relation and eating different types of foods. We used a self-report questionnaire designed by the investigators. The questionnaire consisted of 21 questions that covered different aspects of female sexuality and its relation to food.

Results: Most of the participants (63\%) were in the age group of 30-39 years. The commonest coital frequency was - two to three times per week, which was suitable for $45.7 \%$ of the studied women. On the other hand, spontaneous desire was reported by $43 \%$ of women to occur - two to three times per week. Among our sample, $50.3 \%$ were exposed to female genital mutilation/cutting. Regarding sexual satisfaction, $47.3 \%$ reported being moderately satisfied and 38.3\% were very satisfied and almost one-third of women $(32.3 \%)$ can reach orgasm in more than half the times of sexual encounters.

Among participants, $85 \%$ consider that the positive effects of food were increasing libido, increasing orgasm (11\%), and prolonging the time of lubrication (4\%). On the other hand, oils were found to decrease libido $(31.8 \%)$ and have a negative effect on orgasm (36.4), while white meat was the commonest food to decrease lubrication (50\%).

Seafood was the most common type of food that improved husband's sexual activity (78\%) followed by nuts (25.3\%).

Conclusion: Our women sample believes that some kinds of food can positively or negatively affect their sexuality as well as sexual performance of their husbands.
\end{abstract}

Key Words: Female, food, sexual functions, women.

Received: 02 August 2021, Accepted: 16 August 2021

Corresponding Author: Ihab Younis, Department of Dermatology and Andrology, Faculty of Medicine, Benha University, Benha, Egypt, Tel.: 01017186419, E-mail: ihabyounis@hotmail.com

ISSN: 2090-6048, 2021

\section{INTRODUCTION}

The relation between food and sexuality was a subject of controversy throughout history. From the Hindu poems Samhita of Sushruta (science of life), inscribed around 2000-1000BC, it is clear that since ancient times, human beings have searched for substances to enhance sexual experience. The poem contains descriptions of 'natural' remedies that are ways to gratify every sense with good food, music, perfumes, appropriate surroundings, and, not the least, adequate partners. It includes treatments, consisting of either recipes with high nutritional value or heavy metal oxides mixed with musk and amber and, for good measure, spice ${ }^{[1]}$.

In Genesis 30:14, Rachel quarreled with Leah about who should eat the mandrakes gathered by Reuben because each wife wanted to eat them in order to stimulate desire in $\mathrm{Jacob}^{[2]}$.
History has woven quite a collection of folklore, mythology, and superstition around the sexual nature of food. If you look hard enough, you will discover that pretty much every food has been shown as an aphrodisiac at one point or another in history. While most of aphrodisiac mythology stems from foods with symbolic colors or shapes (e.g. similarity of oysters to vagina), certain foods do contain properties that stimulate pleasure centers in the brain. Whether or not these foods can actually enhance amorous feelings is up for debate ${ }^{[3]}$.

The role of diet in sexual health is an area of study that is gaining attention from the scientific community. Previous research at this point has focused on male sexual dysfunction, with less emphasis on the correlation between diet and female sexuality. Preliminary data are sparse, but it seems that diet can influence sexuality mainly through correction of the underlying metabolic pathophysiology that can result from such comorbidities ${ }^{[4]}$. 
There is still a wide gap in our knowledge regarding diet and its influence over female sexual health. Much more of the contemporary literature has focused on comorbidities such as metabolic syndrome and obesity and their subsequent impact on sexual functioning ${ }^{[3]}$.

The research question of the current work was how does food influence female sexuality according to the views of a sample of Egyptian women.

\section{PATIENTS AND METHODS}

This cross-sectional study included 300 married women having a regular sexual activity and eating different types of foods. Participants were women attending the outpatient clinic of Benha University Hospital during the period from February 2020 to March 2021.

The study was approved by the Research Ethical Committee (dating 12/2019), and Dermatology and Andrology Department, Faculty of Medicine, Benha University.

The tool of the study was a self-report questionnaire designed by the investigators. The aim of the study and the details of the questionnaire were explained to the women before taking their informed consent, with the investigators remaining accessible if participants needed clarification. Privacy and confidentiality were secured.

The questionnaire included questions that covered demographic data and female sexual functions. The questionnaire also included a list of common food types to let participants determine their possible positive or negative impact on their sexuality as well as the sexuality of their husbands.

Excluded from the study were women who are vegetarian, severely ill, or illiterate.

\section{Data management}

The clinical data were recorded on a report form. These data were tabulated and analyzed using the computer program SPSS (Statistical Package for Social Science), version 20) IBM Corp., Armonk, New York, USA (to obtain:

Descriptive data in the form of frequency and distribution for qualitative data.

Analytical statistics :intergroup comparison of categorical data was performed by using $\chi 2$ and Fisher exact test. A $P$ value less than 0.05 was considered statistically significant, while more than 0.05 statistically insignificant $P$ value less than 0.01 was considered highly significant in all analyses.

\section{RESULTS}

\section{Demographic data}

The commonest age group of participants was 30-39 years $(63 \%)$. Most women $(87 \%)$ were living in rural areas, have university education $(98.3 \%)$, and employed (74\%) (Table 1).

\section{Sexual activity}

The commonest coital frequency in our sample was two to three times/week (45.7\%). Lubrication and orgasm can be obtained in almost every sexual encounter in 41 and $32.3 \%$ of women, respectively. The majority of women (65.7\%) masturbated before marriage and $29.9 \%$ still do after marriage. Almost half of the sample (49.7\%) were exposed to female genital mutilation/cutting and $47.3 \%$ were moderately satisfied with their sexual life. The majority of our sample $(66.3 \%)$ think that some types of food affect their sexual functions. These foods increase libido in $85 \%$ of the sample (Table 2).

\section{Foods that positively affect female sexual functions}

The most common three foods that enhance female libido were seafood $(59.2 \%)$, chocolate $(40.4 \%)$, and nuts $(28.2 \%)$. The same three foods were reported to help women achieve orgasm (chocolate: $54.5 \%$, seafood: $45.5 \%$, and nuts: $39.4 \%$ ). Foods that most commonly facilitate lubrication were seafood $(66.7 \%)$, chocolate $(41.7 \%)$, and fruits $(33.3 \%)$ (Table 3$)$.

Table 1: Demographic data of participants

\begin{tabular}{lc}
\hline Variables & Studied group $(\mathrm{N}=300)[\mathrm{n}(\%)]$ \\
\hline Age & \\
$20-29$ & $87(29)$ \\
$30-39$ & $189(63)$ \\
$40-50$ & $23(7.7)$ \\
$50+$ & $1(0.3)$ \\
Residence & \\
Urban area & $39(13)$ \\
Rural area & $261(87)$ \\
\hline
\end{tabular}




\begin{tabular}{lc}
\hline Educational level & \\
Read and write & $1(0.3)$ \\
Finished 2ry school & $4(1.3)$ \\
University degree & $295(98.3)$ \\
Employment & \\
Housewife & $43(14.3)$ \\
Employee & $222(74)$ \\
Has your own business & $35(11.7)$ \\
\hline
\end{tabular}

Table 2: Sexual activity

\begin{tabular}{|c|c|}
\hline Variables & Studied group $(\mathrm{N}=300)[\mathrm{n}(\%)]$ \\
\hline \multicolumn{2}{|l|}{ Coital frequency } \\
\hline Daily & $24(8.0)$ \\
\hline $2-3$ times per week & $137(45.7)$ \\
\hline 1 time per week & $88(29.3)$ \\
\hline $1-2$ times per month & $36(12.0)$ \\
\hline Less than that & $15(5.0)$ \\
\hline \multicolumn{2}{|l|}{ Lubrication } \\
\hline Almost all times of sexual encounters & $123(41)$ \\
\hline More than half the times of sexual encounters & $82(27.3)$ \\
\hline About half the times of sexual encounters & $35(11.7)$ \\
\hline Less than half the times of sexual encounters & $38(12.7)$ \\
\hline Rarely or almost never & $22(7.3)$ \\
\hline \multicolumn{2}{|l|}{ Reaching orgasm } \\
\hline Every time of sexual encounters & $97(32.3)$ \\
\hline More than half the times of sexual encounters & $87(29)$ \\
\hline About half the times of sexual encounters & $38(12.7)$ \\
\hline Less than half the times of sexual encounters & $39(13)$ \\
\hline Rarely or almost never & $39(13)$ \\
\hline \multicolumn{2}{|l|}{ Have you ever masturbated before marriage? } \\
\hline Yes & $197(65.7)$ \\
\hline No & $103(34.3)$ \\
\hline \multicolumn{2}{|l|}{ Do you still masturbate } \\
\hline Yes & $9(29.9)$ \\
\hline No & $138(70.1)$ \\
\hline \multicolumn{2}{|l|}{ Female genital mutilation/cutting } \\
\hline Yes & 149 (49.7) \\
\hline No & $151(50.3)$ \\
\hline \multicolumn{2}{|l|}{ Satisfaction with overall sexual life } \\
\hline Very satisfied & $115(38.3)$ \\
\hline Moderately satisfied & $142(47.3)$ \\
\hline Dissatisfied & $43(14.3)$ \\
\hline \multicolumn{2}{|l|}{ Do you think that food affects your sexual behavior? } \\
\hline Yes & $199(66.3)$ \\
\hline No & 101(33.7) \\
\hline
\end{tabular}




\begin{tabular}{lc}
\hline How can you describe the positive effect of food on your sexual activity? & $255(85)$ \\
Increases your libido & $33(11)$ \\
Increases your orgasm & $12(4)$ \\
Prolong the time of lubrication
\end{tabular}

Table 3: Foods that positively affect female sexual functions

\begin{tabular}{lccccc}
\hline Variables & $\begin{array}{c}\text { Libido }(\mathrm{N}=255) \\
{[\mathrm{n}(\%)]}\end{array}$ & $\begin{array}{c}\text { Orgasm(N=33) } \\
{[\mathrm{n}(\%)]}\end{array}$ & $\begin{array}{c}\text { Lubrication } \\
(\mathrm{N}=12)[\mathrm{n}(\%)]\end{array}$ & FET & $P$ value \\
\hline Vegetables & $27(10.6)$ & $5(15.2)$ & $3(25)$ & 2.75 & 0.25 \\
Herbs & $8(3.1)$ & $1(3.0)$ & $4(33.3)$ & 25.36 & $0.001^{* *}$ \\
Red meat & $26(10.2)$ & $5(15.2)$ & $2(16.7)$ & 1.14 & 0.57 \\
White meat & $8(3.1)$ & $3(9.1)$ & $2(16.7)$ & 7.09 & $0.029^{*}$ \\
Seafood & $151(59.2)$ & $15(45.5)$ & $8(66.7)$ & $\chi 2=2.66$ & 0.27 \\
Nuts & $72(28.2)$ & $13(39.4)$ & $3(25)$ & $\chi 2=1.87$ & 0.39 \\
Fruits & $36(14.1)$ & $7(21.2)$ & $4(33.3)$ & $\chi 2=4.07$ & 0.13 \\
Oils & $4(1.6)$ & 0 & $2(16.7)$ & 14.09 & $0.001^{* *}$ \\
Drinks & $14(5.5)$ & $4(12.1)$ & $3(25)$ & 8.2 & $0.017^{*}$ \\
Chocolate & $103(40.4)$ & $18(54.5)$ & $5(41.7)$ & $\chi 2=2.4$ & 0.30 \\
Other foods & $33(12.9)$ & $2(6.1)$ & $2(16.7)$ & 1.50 & 0.47 \\
\hline
\end{tabular}

$\chi 2, \chi 2$ test; FET, Fisher's exact test ; *Significant ; **Highly significant.

\section{Foods that negatively affect female sexual functions}

A decrease in libido on eating oils, red meat, and herbs was reported by $31.8,21.2$, and $20.4 \%$ of women, respectively. The three commonest foods that are accompanied by difficulty to achieve orgasm were oils (36.4\%), red meat (36.4\%), and herbs $(15.2 \%)$. As reported by participants, the ability to be lubricated was decreased on eating white meat $(50 \%)$, red meat $(41.7 \%)$, and oils $(33.3 \%)$ (Table 4).

\section{Foods that affect husband's sexual functions}

According to wives, husband's libido increases on

Table 4: Foods that negatively affect female sexual functions eating seafood $(56.3 \%)$, chocolate $(38.9 \%)$, and nuts (26\%).Consequently, coital frequency is enhanced by eating those foods (seafood: $63.5 \%$, chocolate: $44.2 \%$, and nuts: $36.5 \%$ ). Also, eating those three foods may increase the duration of intercourse (seafood: $60 \%$, chocolate: $55 \%$, and nuts:37.5\%).

The commonest three foods associated with a decrease in husband's libido were oils $(29.8 \%)$, herbs $(21.6 \%)$, and red meat (19.7\%). Consequently, those three foods decrease coital frequency (oils: $36.5 \%$, red meat: $21.2 \%$, and herbs: $19.2 \%$ ). The duration of intercourse may be negatively affected by eating oils (40\%), red meat (30\%), and herbs (27.5\%) (Table 5).

\begin{tabular}{lccccc}
\hline Variables & Libido $(\mathrm{N}=255)[\mathrm{n}(\%)]$ & Orgasm $(\mathrm{N}=33)[\mathrm{n}(\%)]$ & Lubrication $(\mathrm{N}=12)[\mathrm{n}(\%)]$ & FET & $P$ value \\
\hline Vegetables & $15(5.9)$ & 0 & $2(16.7)$ & 4.72 & 0.094 \\
Herbs & $52(20.4)$ & $12(36.4)$ & $2(16.7)$ & $\chi 2=4.55$ & 0.103 \\
Red meat & $54(21.2)$ & $5(15.2)$ & $5(41.7)$ & $\chi 2=3.71$ & 0.156 \\
White meat & $34(13.3)$ & $3(9.1)$ & $6(50)$ & 13.38 & $0.001^{* *}$ \\
Seafood & $13(5.1)$ & $2(6.1)$ & $2(16.7)$ & 2.88 & 0.237 \\
Nuts & $5(2.0)$ & 0 & $2(16.7)$ & 11.76 & $0.003^{* *}$ \\
Fruits & $4(1.6)$ & 0 & $2(16.7)$ & 14.09 & $0.001^{* *}$ \\
Oils & $81(31.8)$ & $12(36.4)$ & $4(33.3)$ & $\chi 2=0.29$ & 0.87 \\
Drinks & $18(7.1)$ & $2(6.1)$ & $2(16.7)$ & 1.65 & 0.44 \\
Chocolate & $17(6.7)$ & $4(12.1)$ & $4(33.3)$ & 11.37 & $0.003^{* *}$ \\
Other foods & $42(16.5)$ & $3(9.1)$ & $2(16.7)$ & $\chi 2=1.21$ & 0.55 \\
\hline
\end{tabular}

$\chi 2, \chi 2$ test; FET, Fisher's exact test ; **Highly significant. 
Table 5: Foods that affect husband's sexual functions

\begin{tabular}{|c|c|c|c|c|c|}
\hline Variables & Desire $(N=208)[n(\%)]$ & Frequency $(\mathrm{N}=52)[\mathrm{n}(\%)]$ & Duration $(\mathrm{N}=40)[\mathrm{n}(\%)]$ & $\chi 2$ test & $P$ value \\
\hline \multicolumn{6}{|c|}{ Foods that positively affect husband's sexual functions } \\
\hline Vegetables & $19(9.1)$ & $8(15.4)$ & $8(20)$ & 4.69 & 0.096 \\
\hline Herbs & $5(2.4)$ & $4(7.7)$ & $4(10)$ & $\mathrm{FET}=6.38$ & $0.041 *$ \\
\hline Red meat & $19(9.1)$ & $10(19.2)$ & $4(10)$ & 4.38 & 0.11 \\
\hline White Meat & $6(2.9)$ & $3(5.8)$ & $4(10)$ & $\mathrm{FET}=4.41$ & 0.11 \\
\hline Seafood & $117(56.3)$ & $33(63.5)$ & $24(60)$ & 0.96 & 0.62 \\
\hline Nuts & $54(26)$ & $19(36.5)$ & $15(37.5)$ & 3.73 & 0.16 \\
\hline Fruits & $31(14.9)$ & $9(17.3)$ & $7(17.5)$ & 0.30 & 0.86 \\
\hline Oils & $3(1.4)$ & $1(1.9)$ & $2(5)$ & $\mathrm{FET}=2.17$ & 0.34 \\
\hline Drinks & $13(6.3)$ & $3(5.8)$ & $5(12.5)$ & $\mathrm{FET}=2.16$ & 0.34 \\
\hline Chocolate & $81(38.9)$ & $23(44.2)$ & $22(55)$ & 3.68 & 0.16 \\
\hline Other Foods & $26(12.5)$ & $5(9.6)$ & $6(15)$ & 0.62 & 0.73 \\
\hline \multicolumn{6}{|c|}{ Foods that negatively husbands sexual functions } \\
\hline Vegetables & $11(5.3)$ & $1(1.9)$ & $5(12.5)$ & $\mathrm{FET}=4.91$ & 0.09 \\
\hline Herbs & $45(21.6)$ & $10(19.2)$ & $11(27.5)$ & 0.95 & 0.62 \\
\hline Red meat & $41(19.7)$ & $11(21.2)$ & $12(30)$ & 2.12 & 0.35 \\
\hline White meat & $26(12.5)$ & $11(21.2)$ & $6(15)$ & 2.55 & 0.28 \\
\hline Seafood & $12(5.8)$ & $2(3.8)$ & $3(7.5)$ & $\mathrm{FET}=0.58$ & 0.75 \\
\hline Nuts & $3(1.4)$ & $1(1.9)$ & $3(7.5)$ & $\mathrm{FET}=5.45$ & 0.066 \\
\hline Fruits & $4(1.9)$ & 0 & $2(5)$ & $\mathrm{FET}=2.9$ & 0.23 \\
\hline Oils & $62(29.8)$ & $19(36.5)$ & $16(40)$ & 2.1 & 0.35 \\
\hline Drinks & $15(7.2)$ & $3(5.8)$ & $4(10)$ & $\mathrm{FET}=0.61$ & 0.74 \\
\hline Chocolate & $13(6.3)$ & $7(13.5)$ & $5(12.5)$ & $\mathrm{FET}=3.88$ & 0.14 \\
\hline Other foods & $33(15.9)$ & $8(15.4)$ & $6(15)$ & 0.023 & 0.99 \\
\hline
\end{tabular}

$\chi 2, \chi^{2}$ test; FET, Fisher's exact test ; *Significant.

\section{DISCUSSION}

In the previous work examining the views of a sample of Egyptian women about sexual myths ${ }^{[5]}, 54.4 \%$ of female doctors and $64.4 \%$ of nonmedical women believed that seafood boosts libido. The present study not only confirmed this notion, but $59.2 \%$ of women thought that seafood enhances their libido but also they thought that it enhances their husbands' libido. The popularity of seafood as an aphrodisiac is deep rooted in history. Galen (129-199), prescribed oysters as a cure for declining sexual desire. During the Middle Ages, it was generally known that the oyster 'exciteth Venus'(excites beautiful women). But even in earlier societies, there has been overwhelming evidence of the magical beliefs in shells, as the resemblance between the mollusk shell and the female genital organ helped believing in this association ${ }^{[6]}$. Giacomo Casanova, the $18^{\text {th }}$ century famous lover, reportedly ate dozens of oysters at a time to stir arousal before his legendary trysts ${ }^{[3]}$.

The work of Gaskins et al. ${ }^{[7]}$ lends some scientific basis for this belief. Their participants were 501 American couples planning for pregnancy. The aim of the study was of examining the relationship between male and female seafood intake with time to pregnancy. During follow-up, both male and female seafood intake was independently associated with coital frequency, with slightly stronger associations observed for male intake. Furthermore, when both partners consumed eight or more servings per cycle, coital frequency was increased by $21.9 \%$ compared with couples consuming less. In the day-level analyses, the odds of sexual intercourse were $39 \%$ greater if both partners consumed seafood the same day. This result was also observed in our work.

Montezuma II was the ninth Aztec emperor of Mexico in the 16th century. Rumors abounded as to just how he prepared his cacaobeverage before having sexual intercourse with his numerous wives. In the 18th century, Linnaeus identified three kinds of illnesses in which chocolate could be used for treatment: loss of weight, as a consequence of lung and muscle diseases, hypochondria 
and hemorrhoids, adding also that it was an excellent aphrodisiac, confirming a tradition already existing in the Pre-Columbian culture ${ }^{[8]}$. In 1881, Monlau wrote a pamphlet in Spain, on health-related issues for married couples that included the observation that "cacao paste and cocoa butter enhances sexual desire ${ }^{[9]}$.

Looking at chocolate as an aphrodisiac is still observed in modern time. Libido and orgasm were enhanced in our women sample by eating chocolate in 40.4 and $54.5 \%$, respectively. Salonia et al. ${ }^{[10]}$ studied a convenience sample of 153 Italian women. They assessed sexual function [Female Sexual Function Index (FSFI)], sexual distress (Female Sexual Distress Scale), and depression (Beck Depression Inventory and Center for Epidemiological Survey Depression Scale). They divided participants into two groups:group 1 included women answering 'yes' to the question 'Do you usually eat some chocolate cube on a daily basis?' and group 2 included women answering 'no' to the same question. Interestingly, both the FSFI total score and the FSFI sexual desire domain score were significantly higher in women reporting chocolate intake compared with women who did not. However, they warn that their result may be affected by the observation that group-2patients were older than patients in group 1, that is, aging may have an effect on the results.

A biological support for such a proposed explanation is reflected in the inference that "chocolate gets right to the heart of sexual pleasure by increasing the brain's level of serotonin ${ }^{[11]}$. Indeed, chocolate does contain phenylethylamine and stimulates biogenic amines, including serotonin and dopamine as well as catecholamines $^{[12]}$. The differential effects in men versus women could be speculated to align with observations that different brain regions are activated and inhibited by chocolate consumption, and chocolate 'satiety,' in women versus men ${ }^{[13]}$.

Contrary to the above-mentioned results, a recent American study ${ }^{[14]}$ may cast doubt on the stimulant effect of chocolate on libido. The study included 723 Southern California men and women, age more than 20, who completed surveys providing chocolate-consumption frequency and interest in sex. Women who ate chocolate more frequently reported significantly less interest in sex. A qualitatively similar finding was present for analysis of combined men and women. However, the finding was particularly strong among women, and separately significant for women, for whom chocolate-consumption frequency was, indeed, the strongest assessed predictor of sexinterest. On exploratory analysis, younger adult men (underage 55) contributed somewhat to the relationship in the combined-sex sample, but the relationship of more frequent chocolate consumption to lesser sex interest in younger men was materially weaker than the relationship in women, and the significance of the finding was attenuated with adjustments (versus strengthened in women). Older men did not share this relationship.
Nuts (Mekassar at as translated in our survey) ranked in the third place in foods that enhance libido, orgasm, and lubrication. It also was number-3 food to stimulate erection, coital frequency, and duration of intercourse in husbands of our sample. Unfortunately, we could not locate any article dealing with the effect of nuts on female sexuality. Scarce articles dealing with male sexuality are available. The study of Salas-Huetos et al. ${ }^{[15]}$ suggests that compliance with a healthy diet supplemented with mixed nuts may help to improve erectile and sexual desire. Their study did not provide enough evidence to support the main mechanism for these improvements, but they quote Alderson ${ }^{[16]}$ who suggests that absence of evidence is not evidence of absence. Also, almond-supplemented diet enhanced sexual activities, and reduced oxidative stress and pro-inflammatory markers in diabetic male rats ${ }^{[17]}$.

A Turkish study ${ }^{[18]}$ evaluated the effect of eating $100 \mathrm{~g}$ of pistachios daily for 3 weeks on 17 married men complaining of ED. Study participants saw a significant improvement on International Index of Erectile Function scores, which measure orgasmic function, sexual desire, and sexual intercourse satisfaction.

A study on male rats ${ }^{[19]}$, provided a scientific rationale for the traditional use of nutmeg in the management of male sexual disorders. Oral administration of a $50 \%$ ethanolic extract of nutmeg at a dose of $500 \mathrm{mg} / \mathrm{kg}$, produced significant augmentation of sexual activity in male rats. It significantly increased erections, number of intromissions before ejaculation, and caused significant reduction in the time from the introduction of female into the cage of the male up to the first mount and the next intromission by the male after ejaculation. The extract was also observed to be devoid of any adverse effects and acute toxicity.

Prescott and $\mathrm{Khan}^{[20]}$ recently reviewed 53 species of medicinal plants/herbal supplements commonly found in aphrodisiacs on the market in the United States. Most species listed have anecdotal use as aphrodisiacs throughout history; therefore, a systematic search was done for clinical evidence. They concluded that there is little-to-no evidence from the literature to substantiate claims of plants currently sold on the market as aphrodisiacs for female-desire disorders. They added that studies of plants currently used as ingredients for aphrodisiacs are severely lacking, and even so the evidence that exists is weak.

The beneficial effects in female sexuality are claimed for some types of diets. Giugliano et al. ${ }^{[21]}$ found that greater adherence to Mediterranean diet is associated with a lower prevalence of FSD in type-2 diabetic women. A Mediterranean diet is high in vegetables, fruits, legumes, nuts, beans, cereals, grains, fish, and unsaturated fats such as olive oil. Women placed on a very-low-calorie ketogenic diet (a high-fat, adequate-protein, low-carbohydrate diet) saw a statistically significant improvement in mean total score and the excitation and lubrication subdomains of the FSFI. Interestingly, the orgasmic domain also increased 
significantly but only during the maximal ketosis phase of the $\operatorname{diet}^{[4]}$

\section{LIMITATIONS OF THE STUDY}

The male factor was not assessed directly but through their wives. Possible determinants of sexual dysfunction such as female genital mutilation, vaginitis, pelvic inflammatory diseases, and urinary-tract infection were not evaluated in this report.

\section{CONCLUSION}

Seafood, chocolate, and nuts were the three foods reported mostly by our sample to enhance libido, and help obtaining orgasm. Fruits were also reported to commonly facilitate lubrication. Also, seafood, chocolate, and nuts were reported by women to enhance libido, coital frequency, and duration in their husbands.

\section{CONFLICT OF INTEREST}

There are no conflicts of interst.

\section{REFERENCES}

1. Hollister LE. Drugs and sexual behavior in man. Life Sci1975; 17:661-667.

2. Walker A R. Dietary advice: from folklore to present beliefs. Nutr Rev1995; 53:8-10.

3. Avey T. Learn why these 10 foods are edible aphrodisiacs. Available at: https://www.pbs.org/ food/the-history-kitchen/10-edible-aphrodisiacs/ [Accessed July 12, 2021].

4. Towe M, La J, El-Khatib F, Roberts N, Yafi F A, Rubin R. Diet and female sexual health. Sex Med Rev2020; 8:256-264.

5. Younis I, Ibrahim M A, Abdel-Munem F A. Believe it or not: views of a sample of Egyptian women about sexual myths. Hum Androl2021; 11:1-0.

6. The Ibizan. 2021. Casanova and the aphrodisiac oyster. Available at: https://theibizan.com/casanovaand-the-aphrodisiac-oyster/. [Accessed July 15, 2021].

7. Gaskins A J, Sundaram R, Buck Louis G M, Chavarro J E. Seafood intake, sexual activity, and time to pregnancy. J Clin Endocrinol Metab2018; 103:2680-2688.

8. Lippi D. Chocolate in history: food, medicine, medifood. Nutrients2013; 5:1573-1584.

9. Dillinger T L, Barriga P, Escárcega S, Jimenez M, Salazar Lowe D, Grivetti L E. Food of the gods: cure for humanity? A cultural history of the medicinal and ritual use of chocolate. J Nutr2000; 130(8S Suppl):2057S-2072SS.

10. Salonia A, Fabbri F, Zanni G, Scavini M, Fantini G $\mathrm{V}$, Briganti A, et al. Chocolate and women's sexual health: an intriguing correlation. J Sex Med2006; $3: 476-482$.

11. Chocolate: the love drug....and why it's good for you. Available at: https://www.foxnews.com/health/ chocolate-the-love-drug-and-why-its-good-for-you. [Accessed July, 2021].

12. Millen M M, Golomb B A. Chocolate: mood. In: Watson R R, Preedy V R and Zibadi S(editors). Chapter 30. Chocolate in health and nutrition. New York: Springer; 2012. 409-420.

13. Smeets P A, de Graaf C, Stafleu A, van Osch M J, Nievelstein R A, van der Grond J. Effect of satiety on brain activation during chocolate tasting in men and women. Am J Clin Nutr2006; 83:1297-1305.

14. Golomb B A, Berg B K. Chocolate consumption and sex-interest. Cureus2021; 13:e13310.

15. Salas-Huetos A, Muralidharan J, Galiè1 S, SalasSalvadó J, Bulló M. Effect of nut consumption on erectile and sexual function in healthy males: a secondary outcome analysis of the FERTINUTS randomized controlled trial. Nutrients2019; 11:1372.

16. Alderson P. Absence of evidence is not evidence of absence. BMJ1995; 328:476-477.

17. Adebayo A, Oboh G, Ademosun A O. Effect of dietary inclusion of almond fruit on sexual behavior, arginase activity, pro-inflammatory, and oxidative stress markers in diabetic male rats. J Food Biochem2021; 45:e13269.

18. Aldemir M, Okulu E, Neselioglu S, Erel O, Kayigil O. Pistachio diet improves erectile function parameters and serum lipid profiles in patients with erectile dysfunction. Int J Impot Res2011; 23:32-38.

19. Tajuddinø, Ahmad S, Latif A, Qasmi I A, Amin K M An experimental study of sexual function improving effect of Myristica fragrans Houtt. (nutmeg). BMC Complement Altern Med2005; 5:16.

20. Prescott H, Khan I. Medicinal plants/herbal supplements as female aphrodisiacs: does any evidence exist to support their inclusion or potential in the treatment of FSD?. J Ethnopharmacol2020; 251:112464.

21. Giugliano F, Maiorino M I, Di Palo C, Autorino $\mathrm{R}$, De Sio $\mathrm{M}$, Giugliano $\mathrm{D}$, Esposito $\mathrm{K}$. Adherence to Mediterranean diet and sexual function in women with type 2 diabetes. J Sex Med2010; 7:1883-1890. 